Pontifícia Universidade C $_{\text {atólica }}$

Sérgio Gonçalves Mendes

LITURGIA E MORAL SEXUAL: As implicações éticas de uma aproximação mistagógica ao Ritual de Iniciação Cristã de Adultos

Tese de Doutorado

Tese apresentada ao Departamento de Teologia da PUC-Rio, como requisito parcial para obtenção do título de Doutor em Teologia.

Orientadora: Profa. Maria Clara Luchetti Bingemer

Volume I

Rio de Janeiro

Setembro de 2015 
Sérgio Gonçalves Mendes

\title{
Liturgia e Moral Sexual: As implicações éticas de uma aproximação mistagógica ao Ritual de Iniciação Cristã de Adultos
}

Tese apresentada como requisito parcial para obtenção do grau de Doutor pelo Programa de Pós-Graduação em Teologia do Departamento de Teologia do Centro de Teologia e Ciências Humanas da PUC-Rio. Aprovada pela Comissão Examinadora abaixo assinada.

\author{
Prof ${ }^{a}$. Maria Clara Lucchetti Bingemer \\ Orientadora \\ Departamento de Teologia - PUC-Rio
}

Prof. Abimar Oliveira de Moraes Departamento de Teologia - PUC-Rio

Prof. Luiz Fernando Ribeiro Santana

Departamento de Teologia - PUC-Rio

Prof. Luis Carlos Susin

$\mathrm{PUC} / \mathrm{RS}$

Prof. Nilo Ribeiro Júnior

UNICAP

Prof ${ }^{a}$. Denise Berruezo Portinari

Coordenadora Setorial de Pós-Graduação e Pesquisa do Centro de Teologia e Ciências Humanas - PUC-Rio

Rio de Janeiro, 28 de setembro de 2015. 
Todos os direitos reservados. É proibida a reprodução total ou parcial do trabalho sem autorização da universidade, do autor e do orientador.

\section{Sérgio Gonçalves Mendes}

Graduou-se em Tecnologia de Processamento de dados (Centro de Ensino Superior de Juiz de Fora - MG) em 1995; em Filosofia (Faculdade Jesuíta de Filosofia e Teologia Belo Horizonte - MG) em 2001; e em Teologia (Faculdade Jesuíta de Filosofia e Teologia - Belo Horizonte - MG) em 2005. Concluiu o Mestrado em Teologia pela Pontifícia Universidade Católica do Rio de Janeiro em 2011. É professor de Filosofia e Ensino Religioso no Ensino Médio na rede particular. É Gestor Administrativo da Rede de Educação Teresiana de Enrique de Ossó.

Ficha Catalográfica

Mendes, Sérgio Gonçalves

Liturgia e moral sexual: as implicações éticas de uma aproximação mistagógica ao ritual de iniciação cristã de adultos / Sérgio Gonçalves Mendes ; orientadora: Maria Clara Luchetti Bingemer. - 2015.

$2 \mathrm{v} . . ; 30 \mathrm{~cm}$

Tese (doutorado)-Pontifícia Universidade Católica do Rio de Janeiro, Departamento de Teologia, 2015.

Inclui bibliografia

1. Teologia - Teses. 2. Moral sexual. 3. Ética teológica. 4. Sexualidade. 5. Mistagogia. 6. Liturgia. I. Bingemer, Maria Clara Luchetti. II. Pontifícia Universidade Católica do Rio de Janeiro. Departamento de Teologia. III. Título. 


\section{Agradecimentos}

Ao Deus Uno e Trino, mistério divino de amor que é a realidade primeira por detrás da presente tese.

A minha esposa Fernanda, pelo apoio e amor, sem os quais esse trabalho não teria sido concluído.

A minha orientadora Maria Clara Luchetti Bingemer, pela capacidade de inspirar, motivar e conduzir para as melhores escolhas na investigação teológica.

Ao meu co-orientador Pe. Luiz Fernando Ribeiro Santana, por sua generosa e paciente ajuda na pesquisa bibliográfica e em várias intuições que perpassam esta investigação.

Ao grupo de orientandos da professora Maria Clara Luchetti Bingemer, por suas preciosas críticas ao longo do processo de desenvolvimento de nosso trabalho.

À PUC-Rio, pelos recursos oferecidos para o desenvolvimento desta investigação. 


\section{Resumo}

Mendes, Sérgio Gonçalves; Bingemer, Maria Clara Luchetti. Liturgia e moral sexual: As implicações éticas de uma aproximação mistagógica ao Ritual de Iniciação Cristã de Adultos. Rio de Janeiro, 2015. 325p. Tese de Doutorado - Departamento de Teologia, Pontifícia Universidade Católica do Rio de Janeiro.

A partir do Concílio Vaticano II e, particularmente, a partir do decreto Optatam Totius, foi pedida uma renovação da Teologia Moral segundo três orientações fundamentais: o resgate da tradição bíblica, o acento na História da Salvação e o vínculo com a Liturgia. Tal renovação se faz urgente e necessária face aos inúmeros desafios para se tratar teologicamente do tema da sexualidade na pós-modernidade. É por essa razão, que a mistagogia da Iniciação Cristã apresenta-se como uma maneira de, simultaneamente, atender aos apelos do Concílio Vaticano II e falar uma linguagem acessível ao ser humano pósmoderno. É, com efeito, a partir de uma aproximação mistágógica ao Ritual de Iniciação Cristã de Adultos que se descortinam uma série de implicações para a ética da sexualidade tais como a comunicabilidade, a relacionalidade, a criatividade, a fecundidade, a ludicidade, a responsabilidade, a esponsabilidade, etc. Tais implicações ampliam o horizonte de possibilidade para se tratar do tema da ética da sexualidade na pós-modernidade, ao mesmo tempo que reorientam essa disciplina teológica à centralidade do mistério pascal de Cristo.

\section{Palavras-chave}

Moral sexual; ética teológica; sexualidade; mistagogia; liturgia; RICA; iniciação cristã; sacramentos; trindade; Vaticano II. 


\section{Abstract}

Mendes, Sérgio Gonçalves; Bingemer, Maria Clara Luchetti (Advisor). Liturgy and Moral Sexual: The ethical implications of a mystagogical approach to the Rite of Christian Initiation of Adults. Rio de Janeiro, 2015. 325p. Doctoral Thesis - Departamento de Teologia, Pontifícia Universidade Católica do Rio de Janeiro.

From the Second Vatican Council and particularly from the decree Optatam Totius, a renewal of Moral Theology was requested in three basic guidelines: the rescue of the biblical tradition, the accent in the Salvation History and the link with the Liturgy. Such renewal is urgent and necessary in meeting the many challenges to talk theologically about the sexuality in post-modernity. Because of that, the mystagogy of Christian Initiation is presented as a way to simultaneously meet the Second Vatican Council appeals and speak a language accessible to postmodern human being. It is, in effect, from a mystagogical approach to the Rite of Christian Initiation of Adults that several implications for the ethics of sexuality such as communicability, relationality, creativity, fertility, playfulness, responsibility, nuptiality, etc., are revealed. Such implications extend the horizon of possibility to address the ethics of sexuality theme in postmodernity, while redirect this theological discipline to the centrality of the Paschal Mystery of Christ.

\section{Keywords}

Sexual Moral; Theological Ethics; Sexuality; Mystagogy; Liturgy; RCIA; Christian Initiation; Sacraments; Trinity; Vatican II. 


\section{Sumário}

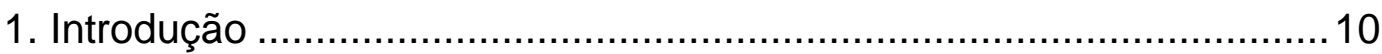

2. A pertinência e a importância do diálogo entre Liturgia e Moral ............24

2.1 Estado da questão e definição do método de investigação ..............24

2.2. A pertinência da relação Liturgia-Moral Sexual .............................52

2.3. A importância da relação Liturgia-Moral Sexual ............................55

2.4. A polifonia do conceito de implicação ética ..................................59

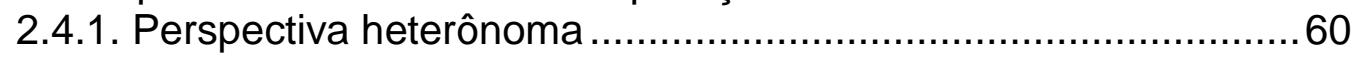

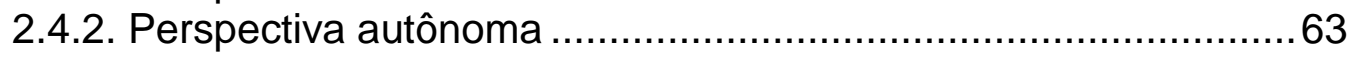

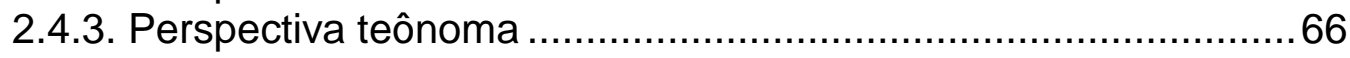

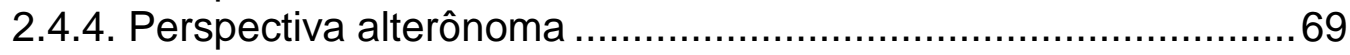

2.5. Conclusão preliminar ………............................................... 74

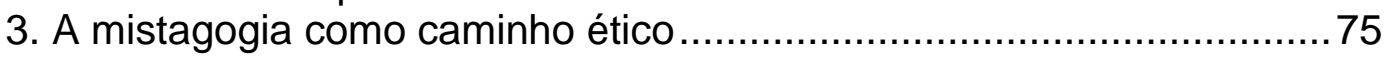

3.1. Os conceitos de mistério e mistagogia ............................................

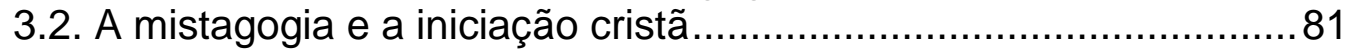

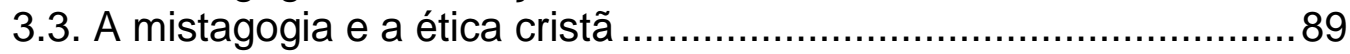

3.4. A mistagogia como evocação do mistério de Jesus de Nazaré.....99

3.5. A mistagogia como provocação: a evangelização e a iniciação

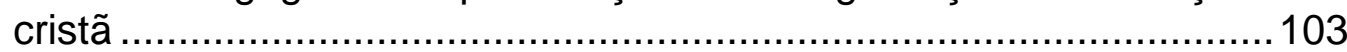

3.6. A mistagogia como convocação: a comunidade de fé ..................106

3.7. A mistagogia como vocação: a inserção na communio trinitária .108

3.7. 1. A singularidade do conceito de "communio" aplicado à

Trindade.

3.7.2. A importância da nomeação trinitária de Deus do RICA para a Moral Sexual........................................................................... 113

3.8. A mistagogia: do Concílio Vaticano II aos nossos dias..................114

3.9 A mistagogia e a ética cristã da sexualidade ...............................131

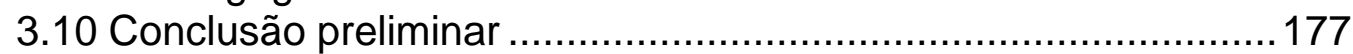

4. As implicações éticas do RICA ...................................................179

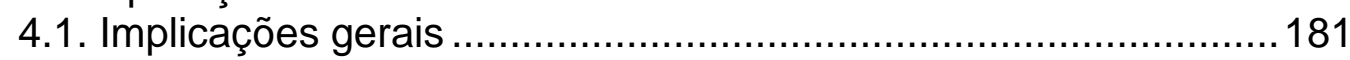

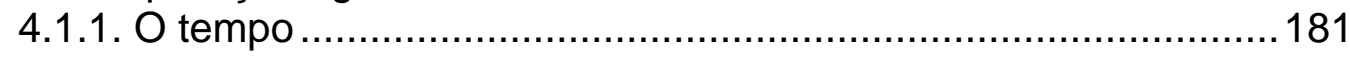

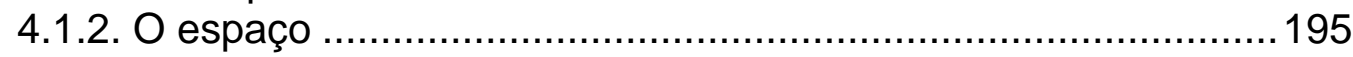

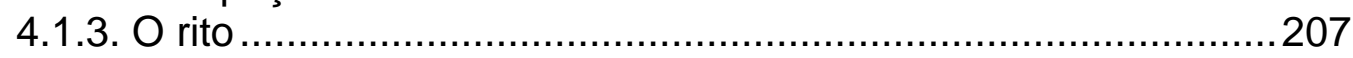

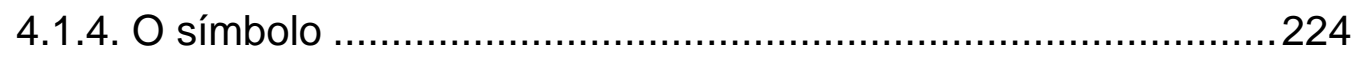

4.1.5. A Palavra de Deus na liturgia ................................................237

4.1.6. A nomeação trinitária de Deus .................................................247

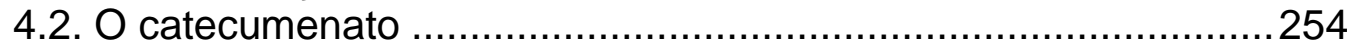

4.3. O tempo da purificação e da iluminação.....................................257

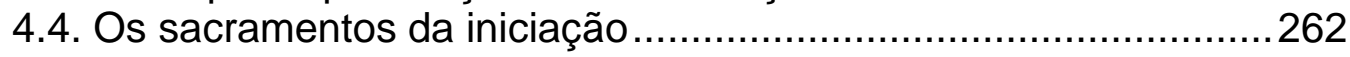

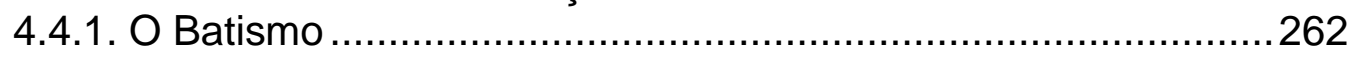

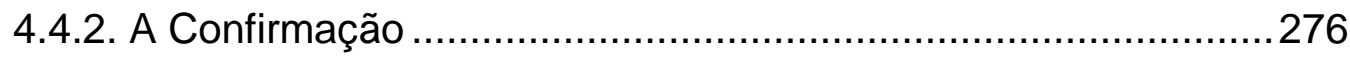

4.4.3. A Eucaristia ................................................................. 278

4.5. Conclusão preliminar e síntese das implicações éticas do RICA 287

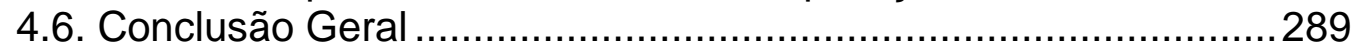

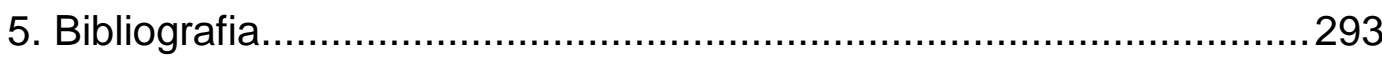




\section{Lista de abreviaturas}

ADS - Carta Encíclica Arcanum Divinae Sapientiae

AG - Decreto Ad Gentes sobre a atividade missionária da Igreja

AFAl - El apostolado de la familia en la actvidad de la Iglesia en el nuevo milenio (CPF)

APPH - Carta aos bispos da Igreja Católica sobre o atendimento pastoral das pessoas homossexuais (CDF)

AT - Antigo Testamento

CC - Carta Encíclica Casti Connubii

CDC - Código de Direito Canônico

CDF - Congregação para Doutrina da Fé

CELAM - Conselho Episcopal Latino Americano

CFL - Exortação Apostólica Christifideles Laici

CGS - Carta do Papa João Paulo II às famílias Gratissimam Sane

CNBB - Conferência Nacional dos Bispos do Brasil

CPF - Conselho Pontifício para a Família

CIC - Catecismo da Igreja Católica

CT - Exortação Apostólica Catechesi Tradendae

DAP - Declaração sobre o Aborto Provocado

DCA - Documento Conclusivo da V Conferência Geral do CELAM em Aparecida-SP

DCE - Carta Encíclica Deus caritas est

DGC - Diretório Geral para a Catequese

DH - Denzinger-Hünermann (Compêndio dos símbolos, definições e declarações de fé e moral)

DV - Constituição Dogmática Dei Verbum

EG - Exortação Apostólica Evangelii Gaudium

EN - Exortação Apostólica Evangelii Nuntiandi

EV - Carta Encíclica Evangelium Vitae

FC - Exortação Apostólica Familiaris Consortio

FMUF - Família, matrimônio e "uniões de fato" (CPF)

GS - Constituição Pastoral Gaudium et Spes

HV - Carta Encíclica Humanae Vitae

IDV - Instrução Donum Vitae - sobre o respeito à vida humana nascente e a dignidade da procriação.

IGMR - Instrução Geral do Missal Romano 
LF - Carta Encíclica Lumen Fidei

LG - Constituição Dogmática Lumen Gentium sobre a Igreja

NT - Novo Testamento

OEAH - Orientações Educativas sobre o Amor Humano (SCEC)

OT - Decreto Optatam Totius sobre a Formação Sacerdotal

PCTL - Pontifício Conselho para Textos Legislativos

$\mathrm{PH}$ - Declaração Persona Humana

PO - Decreto Presbyterorum Ordinis sobre o ministério e a vida dos sacerdotes

PSM - Preparação para o Sacramento do Matrimônio (CPF)

RICA - Ritual da Iniciação Cristã de Adultos

RCE - Carta a respeito da Recepção da Comunhão Eucarística por Fiéis Divorciados Novamente Casados (CDF)

RLUPH - Considerações sobre os projetos de reconhecimento legal das uniões entre pessoas homossexuais (CDF)

SC - Constituição Conciliar Sacrosanctum Concilium

SCEC - Sagrada Congregação para a Educação Católica

$\mathrm{SH}$ - Sexualidade Humana: verdade e significado (CPF)

UR - Unitatis Redintegratio (Vaticano II)

Vaticano II - Concílio Ecumênico Vaticano II

VC - Vademecum para os confessores sobre alguns temas de moral relacionados com a vida conjugal (CPF)

VS - Carta Encíclica Veritatis Splendor 